\title{
RESEARCH
}

Open Access

\section{Behavioral and electrophysiological evidence for a neuroprotective role of aquaporin-4 in the 5xFAD transgenic mice model}

Yoichiro Abe ${ }^{1,2^{*}}$ (D) Natsumi Ikegawa ${ }^{3}$, Keitaro Yoshida ${ }^{4}$, Kyosuke Muramatsu $^{5}$, Satoko Hattori ${ }^{6}$, Kenji Kawai $^{7}$, Minetaka Murakami ${ }^{3}$, Takumi Tanaka ${ }^{3}$, Wakami Goda ${ }^{7}$, Motohito Goto ${ }^{7}$, Taichi Yamamoto ${ }^{7}$, Tadafumi Hashimoto ${ }^{5}$, Kaoru Yamada ${ }^{5}$, Terumasa Shibata ${ }^{1,8}$, Hidemi Misawa ${ }^{8}$, Masaru Mimura ${ }^{4}$, Kenji F. Tanaka ${ }^{4}$, Tsuyoshi Miyakawa ${ }^{6}$, Takeshi Iwatsubo ${ }^{5}$, Jun-ichi Hata ${ }^{7}$, Takako Niikura ${ }^{3}$ and Masato Yasui ${ }^{1,2^{*}}$

\begin{abstract}
Aquaporin-4 (AQP4) has been suggested to be involved in the pathogenesis of neurodegenerative diseases including Alzheimer's disease (AD), which may be due to the modulation of neuroinflammation or the impairment of interstitial fluid bulk flow system in the central nervous system. Here, we show an age-dependent impairment of several behavioral outcomes in 5xFAD AQP4 null mice. Twenty-four-hour video recordings and computational analyses of their movement revealed that the nighttime motion of AQP4-deficient 5XFAD mice was progressively reduced between 20 and 36 weeks of age, with a sharp deterioration occurring between 30 and 32 weeks. This reduction in nighttime motion was accompanied by motor dysfunction and epileptiform neuronal activities, demonstrated by increased abnormal spikes by electroencephalography. In addition, all AQP4-deficient 5xFAD mice exhibited convulsions at least once during the period of the analysis. Interestingly, despite such obvious phenotypes, parenchymal amyloid $\beta$ (AB) deposition, reactive astrocytosis, and activated microgliosis surrounding amyloid plaques were unchanged in the AQP4-deficient 5xFAD mice relative to 5xFAD mice. Taken together, our data indicate that AQP4 deficiency greatly accelerates an age-dependent deterioration of neuronal function in 5xFAD mice associated with epileptiform neuronal activity without significantly altering $A \beta$ deposition or neuroinflammation in this mouse model. We therefore propose that there exists another pathophysiological phase in AD which follows amyloid plaque deposition and neuroinflammation and is sensitive to AQP4 deficiency.
\end{abstract}

Keywords: 5xFAD, Alzheimer's disease, Amyloid $\beta$, Aquaporin-4, Epilepsy

\footnotetext{
*Correspondence: yoabe@a6.keio.jp; myasui@a3.keio.jp

'Department of Pharmacology, Keio University School of Medicine, 35

Shinanomachi, Shinjuku-ku, Tokyo 160-8582, Japan

Full list of author information is available at the end of the article
}

\section{$\triangle B M C$}

(c) The Author(s). 2020 Open Access This article is licensed under a Creative Commons Attribution 4.0 International License, which permits use, sharing, adaptation, distribution and reproduction in any medium or format, as long as you give appropriate credit to the original author(s) and the source, provide a link to the Creative Commons licence, and indicate if changes were made. The images or other third party material in this article are included in the article's Creative Commons licence, unless indicated otherwise in a credit line to the material. If material is not included in the article's Creative Commons licence and your intended use is not permitted by statutory regulation or exceeds the permitted use, you will need to obtain permission directly from the copyright holder. To view a copy of this licence, visit http://creativecommons.org/licenses/by/4.0/ The Creative Commons Public Domain Dedication waiver (http://creativecommons.org/publicdomain/zero/1.0/) applies to the data made available in this article, unless otherwise stated in a credit line to the data. 


\section{Introduction}

Alzheimer's disease (AD) is a progressive neurodegenerative disorder and is the most common cause of dementia. Histopathologically, AD is characterized by senile plaques, extracellular deposits consisting mainly of amyloid $\beta(A \beta)$ peptide, and neurofibrillary tangles, intraneuronal deposits of hyperphosphorylated tau protein. It is well known that reactive astrocytes and activated microglia accumulate around these amyloid plaques in both $\mathrm{AD}$ patients and mouse models of $\mathrm{AD}$, and the subsequent neuroinflammation is thought to be involved in $\mathrm{AD}$ pathogenesis $[6,19,39,45]$.

Aquaporin-4 (AQP4) is the most abundant water channel in the central nervous system (CNS), contributing to water and ion homeostasis, and is strongly expressed in the perivascular and subpial end-feet of astrocytes [38], although a lower degree of AQP4 polarization to perivascular astrocytic end-foot membranes in humans compared with mice due to higher AQP4 expression in parenchymal astrocytic membranes in human brains was observed [10]. It has been reported that the expression of AQP4 is upregulated around amyloid plaques in $\mathrm{AD}$ patients and mouse models of $\mathrm{AD}[14,15,57-59]$, but the functional significance of these findings are unclear. Interestingly, the AQP4 deficiency in mice modifies neuroinflammatory responses in various situations. For example, astrocytosis and/or microgliosis caused by traumatic acute brain damage were shown to be diminished in AQP4 knockout (KO) mice [17, 33, 44, 46]. Similarly, neuroinflammation induced by lipopolysaccharide (LPS) or experimental autoimmune encephalomyelitis (EAE) was attenuated in AQP4 KO mice, showing the neuroprotective effect of AQP4 deficiency [31, 32, 34]. In contrast, in models of chronic Parkinson's disease [50], cryoinjury [46], and focal cerebral ischemia [47] AQP4 deficiency enhanced neuroinflammation, leading to severe neuronal damage. Thus, these findings suggest that AQP4 function might also be implicated in the pathogenesis of $\mathrm{AD}$.

Recently, a CNS interstitial solute clearance system known as the glymphatic system has been proposed [18]. In this system, interstitial metabolites and waste, including $\mathrm{A} \beta$, are transported to perivenous spaces surrounding the large deep veins, accompanied by the convective flow of interstitial fluid (ISF). This is driven by the efflux of cerebrospinal fluid (CSF) from the subarachnoid space into the brain parenchyma through paravascular spaces in the same direction as blood flow. This requires AQP4 function $[18,28,36]$, suggesting a role for AQP4 in AD pathogenesis which is not associated with neuroinflammation.

Here, we investigated whether AQP4 is involved in the primary neurodegenerative course of $\mathrm{AD}$, namely the deposition of amyloid plaques and neuroinflammation, or the subsequent events of $\mathrm{AD}$ pathogenesis. For this purpose, we utilized 5xFAD mice as an Alzheimer's model, and 5xFAD mice deficient in AQP4. 5xFAD mice are one of the most widely used models for $\mathrm{AD}$ and produce high levels of $A \beta_{42}$ and immediately accumulate amyloid plaques by 2 months of age [40]. Using this model, we found an age-dependent deterioration of neuronal function in $5 x F A D$ mice which is sensitive to AQP4 deficiency and progresses independently of $A \beta$ deposition or neuroinflammation.

\section{Materials and methods \\ Animals}

AQP4 knockout mice were generated as described previously [17] (acc. No. CDB0758 K: http://www.cdb.riken.jp/ arg/mutant\%20mice\%20list.html) and maintained by crossing with C57BL/6JJcl (CLEA Japan Inc. Tokyo, Japan). B6.Cg-Tg (APPSwFlLon,PSEN1*M146L*L286V)6799Vas/ Mmjax (5xFAD) [40] were obtained from Mutant Mouse Resource \& Research Centers. The mice were housed in polycarbonate cages (3-4 animals per cage) at $22-24{ }^{\circ} \mathrm{C}$ under a $12 \mathrm{~h}$ light $/ 12 \mathrm{~h}$ dark cycle with food and water ad libitum. Numbers of mice used in this study are shown in Supplemental Table S1. We detected age-dependent reduction in body weight of $5 x F A D$ mice (Supplemental Fig. S1a), which has also reported previously [23], and we did not see an effect of AQP4 deficiency on the reduction in body weight of $5 x F A D$ aged around 8 month (Supplemental Fig. S1a).

\section{Reverse transcription quantitative polymerase chain reaction (RT-qPCR)}

Total RNA was extracted from cerebral hemispheres with Isogen (Nippon Gene Co., Ltd., Toyama, Japan). First-strand cDNAs were synthesized using SuperScript VILO Master Mix (Thermo Fisher Scientific, Waltham, MA). The qPCR analysis was performed using KOD SYBR qPCR mix (Toyobo) and the Applied Biosystems StepOne Real Time PCR system (Thermo Fisher Scientific). Primers used for the qPCR are listed in Supplemental Table S2.

\section{Immunohistochemistry}

Mouse brain slice sections were prepared as described previously [12] with slight modifications. Paraffin sections with thickness of $5 \mu \mathrm{m}$ was subjected to immunostaining using a Lica Bond-Max automatic immunostainer (Leica Biosystems, Mount Waverley, VIC, Australia). Used antibodies are rabbit anti-beta Amyloid 1-42 antibody (mOC64, 1:1000, abcam, Cambridge, UK) rabbit antiAQP4 (1:30000, Atlas Antibodies AB, Bromma, Sweden), rabbit anti-Glial fibrillary acidic protein (GFAP) (1:2000, abcam), and rabbit anti-Iba1 (1:2000, FUJIFILM Wako Pure Chemical Corporation, Osaka, Japan) antibodies. 
The number and size of plaques were analyzed using ImageJ ver. 2.

\section{Clearing brains}

We used tissue clearing protocol based on a protocol for Clear, Unobstructed Brain/Body Imaging Cocktails and Computational analysis (CUBIC) [29, 51]. Brains were removed from mice anaesthetized by inhalation administration of isoflurane followed by perfusion fixation with $4 \%$ paraformaldehyde (PFA). The brains were immersed in $4 \%$ PFA at $4{ }^{\circ} \mathrm{C}$ for $2 \mathrm{~h}$ and were cut sagittally along the midline. The cerebral hemispheres were further immersed in $4 \%$ PFA at $4{ }^{\circ} \mathrm{C}$ overnight and transferred to $50 \%$ CUBIC-L solution [51] to incubate at $37^{\circ} \mathrm{C}$ for 6 $\mathrm{h}$ with gently shaking. Then the hemispheres were transferred to CUBIC-L [51] to incubate at $37{ }^{\circ} \mathrm{C}$ with gently shaking for 7 days, changing the solution every 2 days. For immunofluorescent staining, the hemispheres were washed with TBS-T for $1 \mathrm{~h}$ followed by washed twice with TBS containing $0.01 \%$ sodium azide for $2 \mathrm{~h}$. Then the hemispheres were stained with Alexa Fluor 488labeled monoclonal anti- $\beta$ amyloid, 1-16 (6E10, 1:200, BioLegend, San Diego, CA) and Amylo-Glo RTD Amyloid Plaque Stain Reagent (1:100, Biosensis, Thebarton, Australia) in TBS containing $0.01 \%$ sodium azide, $0.5 \%$ Triton X-100, and 2.5\% BSA at room temperature for 3 days. The stained hemisphares were washed three times with TBS containing $0.01 \%$ sodium azide and transferred to ScaleCUBIC-2 [29] to incubate at $37^{\circ} \mathrm{C}$ for 2 days with gentle shaking. The cleared brains in $80 \%$ ScaleCUBIC-2 were observed with Lightsheet Z.1 (Carl Zeiss, Oberkochen, Germany). Obtained images were stitched with arivis Vision4D ver. 2.12.3 (arivis AG, Munich, Germany), and analyzed with Imaris ver. 9.1.2 (Biplane AG, Zurich. Switzerland).

One-hundred- $\mu \mathrm{m}$ sections were also cleared using the CUBIC method and stained with Amylo-Glo RTD Amyloid Plaque Stain Reagent, Cy3-conjugated monoclonal anti-GFAP (G-A-5, 1:200, Sigma-Aldrich corp. St. Louis, $\mathrm{MO}$ ), Red Fluorochrome(635)-conjugated rabbit antiIba1 (1:200, FUJIFILM Wako Pure Chemical Corporation), and rabbit anti-AQP4 (1:200, Sigma-Aldrich corp.) followed by Alexa Fluor 488-labeled goat antirabbit IgG (1:200, Thermo Fisher Scientific). The sections were mounted on a slide using ProLong ${ }^{\text {mix }}$ Glass Antifade Mountant (Thermo Fisher Scientific) and observed with LSM 710 laser scanning confocal microscope (Carl Zeiss).

\section{Digital Vivarium}

Vium Digital Smart Houses consist of standard individually ventilated cage slotted in Vium's proprietary rack system. The Digital Vivarium test was described previously [35]. Briefly, Vium Digital Smart Houses are outfitted with sensors and a high-definition camera that enable continuous monitoring of animals. The Vium Digital Platform obtains and maintains a digital record of the data analytics on motion. This study used the validated Vium Motion (m/sec). Daytime motion (collected from 0600 to 1800 PDT), nighttime motion (collected from 1800 to 0600 PDT).

\section{Measurement of $A \beta$}

Extraction of soluble and insoluble $A \beta$ was performed as described in Hashimoto et al. [13]. TBS and 70\% formic acid fractions were used as soluble and insoluble $A \beta$ fractions, respectively. Concentration of $A \beta_{40}$ and $A \beta_{42}$ was determined using Human/Rat $\beta$ Amyloid(40) ELISA Kit Wako II and Human/Rat $\beta$ Amyloid(42) ELISA Kit Wako (FUJIFILM Wako Pure Chemical Corporation, Osaka, Japan), respectively.

For in vivo measuring $A \beta$ concentration in interstitial fluid, mice were anesthetized with isoflurane. A guide cannula (an outer diameter of $0.72 \mathrm{~mm}$ and an inner diameter of $0.64 \mathrm{~mm}$; Eicom, Kyoto, Japan) was stereotactically inserted in the right hippocampus (AP: - 3.1 $\mathrm{mm}$ and LT: $2.5 \mathrm{~mm}$ from bregma, and V: $1.3 \mathrm{~mm}$ ) [43] and cemented. A dummy cannula (Eicom) was placed in the guide cannula. After 3-5 days of recovery period, mice were subjected to microdialysis under the freely moving condition (AtmosLM system, Eicom). A 2-mm microdialysis probe (PEP-4-02, $2 \mathrm{~mm}, 1000 \mathrm{kDa}$ molecular weight cut-off, Eicom) was inserted in the guide cannula and perfusion buffer $(147 \mathrm{mM} \mathrm{NaCl}, 4 \mathrm{mM} \mathrm{KCl}$, $2.3 \mathrm{mM} \mathrm{CaCl}, 0.15 \%$ bovine serum albumin, filtrated with $0.2 \mu \mathrm{m}$ syringe filter) was circulated by peristaltic pump (ERP-10, Eicom) and microsyringe pump (ESP-64, Eicom) at a flow rate of $10 \mu \mathrm{l} / \mathrm{min}$ for $3 \mathrm{~h}$ followed by $1 \mu \mathrm{l} / \mathrm{min}$ for $1 \mathrm{~h}$. After $4 \mathrm{~h}$ of perfusion, samples were collected at $2 \mathrm{~h} /$ fraction in a fraction collector (EFC-96, Eicom) refrigerated at $4{ }^{\circ} \mathrm{C}$. Collected samples were stored at $-80^{\circ} \mathrm{C}$ until ELISA assay.

\section{Electroencephalography}

The animals were deeply anesthetized with a mixture of ketamine and xylazine $(100 \mathrm{mg} / \mathrm{kg}$ and $10 \mathrm{mg} / \mathrm{kg}$, respectively, i.p.) in accordance with guideline from Japanese Association for Laboratory Animal Medicine (JALAM), and then fixed to a stereotaxic apparatus (SM15, Narishige Scientific Instrument, Tokyo, Japan). Their body temperature was maintained at $37 \pm 0.5^{\circ} \mathrm{C}$ using a heating pad (FHC-MO, Muromachi Kikai, Tokyo, Japan) during the surgical procedure. A longitudinal incision was made and the skull surface was exposed. The periosteum and blood were removed thoroughly. Two craniotomies with a diameter of $1 \mathrm{~mm}$ were prepared using a drill. The coordinates of the craniotomies were $0.5 \mathrm{~mm}$ posterior to Bregma, $2.5 \mathrm{~mm}$ lateral from the midline to 
the left for the somatosensory cortex, and $7.5 \mathrm{~mm}$ posterior to Bregma, $0.3 \mathrm{~mm}$ lateral from the midline to the left for the cerebellum [43]. In the individual craniotomies, Teflon-coated silver wire electrodes $(786,500, \mathrm{~A}-\mathrm{M}$ Systems, WA, USA) were implanted above the brain surface as an EEG electrode and a reference. The exposed skull was then covered with a dental cement (SuperBond C\&B, Sun Medical, Shiga, Japan). After completing surgical procedure, the mouse was returned to its homecage for recovery.

After recovery for approximately 1 week, EEG recording was performed. EEG signals were transferred through flexible cables (AWG32, Mogami Cable, Ca, USA) and amplified by 1000-fold, bandpass filtered between 1 and 1000 $\mathrm{Hz}$ (Model 3000, A-M Systems, WA, USA), and digitized at $1000 \mathrm{~Hz}$ using an analog to digital converter (cDAQ9178, National Instruments, TX, USA).

EEG data were analyzed using custom-written programs in MATLAB (2017a, MathWorks, MA, USA). Epileptiform spikes were defined as sharp $(<50 \mathrm{~ms})$ negative deflections with amplitudes exceeding twice the baseline EEG [37]. Number of the epileptiform large EEG waveform in each mouse were counted in all recording sessions.

\section{Grip strength test}

The forelimb grip strength was measured using grip strength meter (O'Hara \& Co., Tokyo, Japan). The mice were lifted by their tails so that their forepaws could grasp a wire grid of the apparatus. The mice were gently pulled backward by the tail until they released the grip. The peak force was recorded in Newton $(\mathrm{N})$.

\section{T-maze test}

Spontaneous alternation task was conducted to assess working memory, as previously described [48]. The mice were subjected to a session consisting of 10 trials. Each trial consisted of a forced choice followed by a free choice. In the forced-choice trial, the mice were forced to enter either the left or right arm of the T-shaped platform of the maze. After the 10-s period, the mouse could return to the starting compartment, and a freechoice trial was started. In the free-choice trial, the mice were allowed to choose one of the arms. The percentage of correct responses in which the mice entered the arm opposite to their choice in the forced-choice trial during the free-choice trial was calculated. Total distance traveled and latency were also measured. Data acquisition and analysis were performed automatically using ImageTM software, based on the public domain ImageJ program (http://rsb.info.nih.gov/ij/), was developed and modified by Tsuyoshi Miyakawa.

\section{Statistical analysis}

For Fig. 2, statistical analysis was performed using SPSS ver. 25 (IBM, Armonk, NY, USA). Data were analyzed using one-way ANOVA, followed by the Bonferroni method. For Figs. 3, 4, 5a, b, and 6; and Supplemental Fig. S5 statistical analysis was performed using JMP ver. 14.0.0 (SAS Institute Inc., Cary, NC, USA). Data were analyzed using two-sided student t-test for Figs. 4, 5a, and b; and one-way ANOVA followed by the TukeyKramer method for Figs. 3 and 6 and Supplemental Fig. S5. For Fig. 5c, d, e, and f, statistical analysis was conducted using Prism5 (GraphPad Software Inc., San Diego, CA, USA). Data were analyzed using two-way ANOVA. For Supplemental Fig. S1, statistical analysis was conducted using StatView (SAS Institute Inc.). Data were analyzed using one-way ANOVA (a, b), two-way repeated measures ANOVA (c, d).

\section{Results \\ AQP4 deficiency accelerated a loss of activity and induced motor dysfunction in female 5xFAD mice}

We observed that female $5 \times \mathrm{xAD} / \mathrm{AQP} 4 \mathrm{KO}$ mice exhibited motor dysfunction, for example demonstrating difficulty in holding food while eating. This phenotype started around 32 weeks of age, and the mice then gradually became immobilized. Males also showed the same phenotype which appeared much later as compared with females. The motor dysfunction was confirmed by an agedependent loss of grip strength (Supplemental Fig. S1b).

To clarify the onset and quantify the degree of this immobility, we observed the behavior of female 5xFAD, AQP4 KO, and 5xFAD/AQP4 KO mice using Digital Vivarium $^{\text {Ta }}$ (Vium, San Mateo, CA), a 24-h video recording and computational analysis system which assesses the movements of individual mice, between 20 and 36 weeks of age. We used female mice since male mice hardly showed behavioral abnormalities during this period, and females exhibited more severe amyloidosis [40]. During the initial 3 weeks of the analysis, all three groups exhibited normal circadian rhythm (Fig. 1a). The system clearly detected an age-dependent reduction in nighttime activity in the 5xFAD/AQP4 KO mice (Fig. 1a, red lines). Average nighttime motion gradually reduced with age, and sharply deteriorated during 30 to 32 weeks of age (Fig. 1b), with the mice exhibiting movement less than $50 \mathrm{~mm} / \mathrm{sec}$. The average age of onset of movement less than $50 \mathrm{~mm} / \mathrm{sec}$ was $28.5 \pm 1.3$ weeks, with a range of 23 to 34 weeks. In contrast, the 5xFAD mice were constantly active during the night throughout the fourmonth analysis period, even compared with the AQP4 $\mathrm{KO}$ mice (Fig. 1a and b, green and blue lines). The analysis system detected that daytime motion in the $5 \times \mathrm{xAD} / \mathrm{AQP} 4 \mathrm{KO}$ mice was also reduced starting at approximately 28 weeks of age (Fig. 1c). 


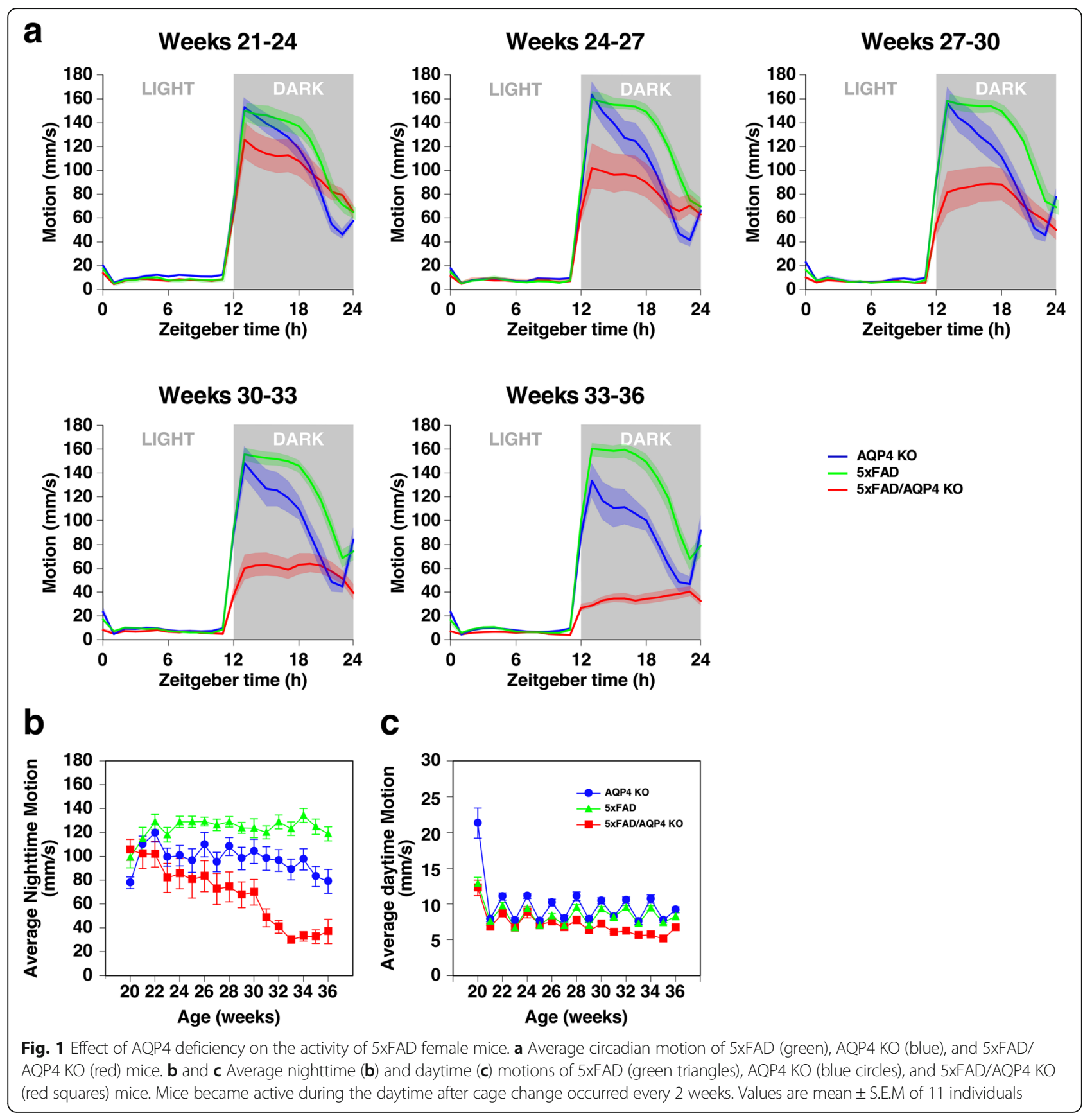

\section{Epileptiform activity in 5xFAD mice}

We found that all $115 x F A D / A Q P 4 \quad K O$ mice exhibited convulsions (Supplemental Movie S1) at least once after the onset of loss of nighttime activity, detected using Digital Vivarium $^{\mathrm{TM}}$. Since multiple AD model animals are known to exhibit epileptiform activity at early stages [2], we hypothesized that $5 x F A D$ mice also have a predisposition to produce epileptiform activity and AQP4 deficiency exacerbates this phenotype. We recorded electroencephalograms (EEG) of the $5 x F A D$ mice at 4 months of age, when $A \beta$ deposition, reactive astrocytosis and activated microgliosis are prominent [40]. In this early stage of the disease, epileptiform spikes were detected, though their frequency was low and no significant difference was noted between the 5xFAD and 5xFAD/AQP4 KO groups (Fig. 2a, b, g and h). However, at 10 months of age, these epileptiform spikes dramatically increased in the $5 x F A D / A Q P 4 \mathrm{KO}$ mice compared with the $5 x F A D$ mice of the same age (Fig. $2 \mathrm{c}$ and $\mathrm{d}$ ). On a number of occasions, we observed convulsions during the EEG recordings (Supplemental Fig. S2 and Supplemental Movie S2), implying that the increase in epileptiform activity results in convulsions. Aged wild-type and AQP4-KO 
a

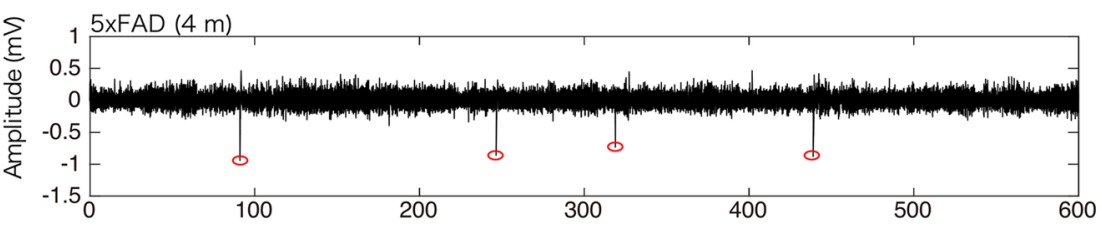

b

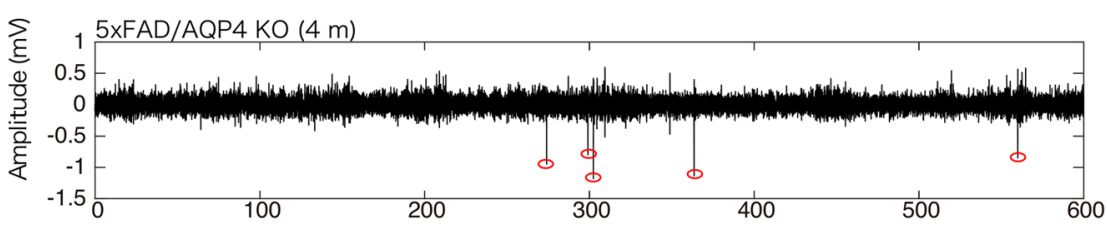

C

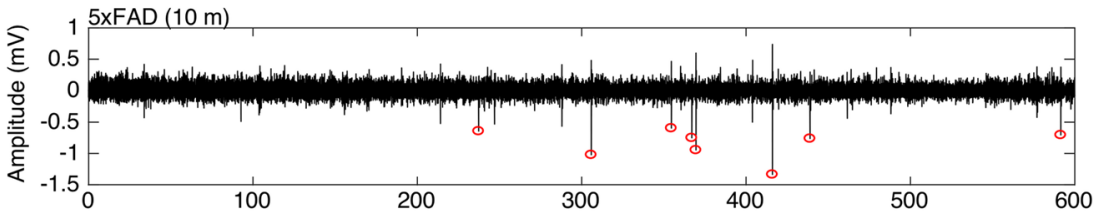

d

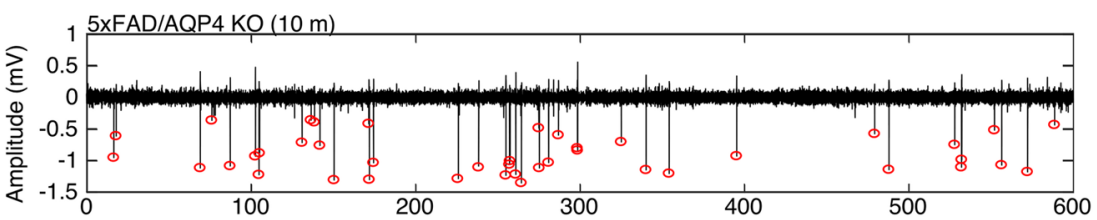

e

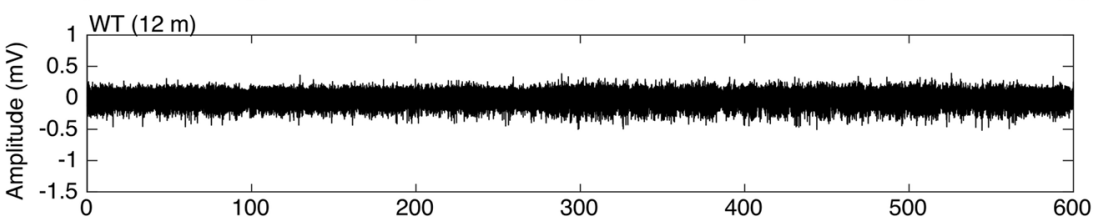

f

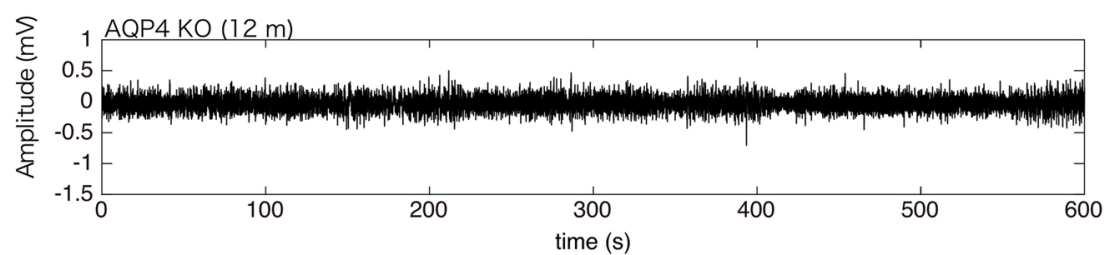

g
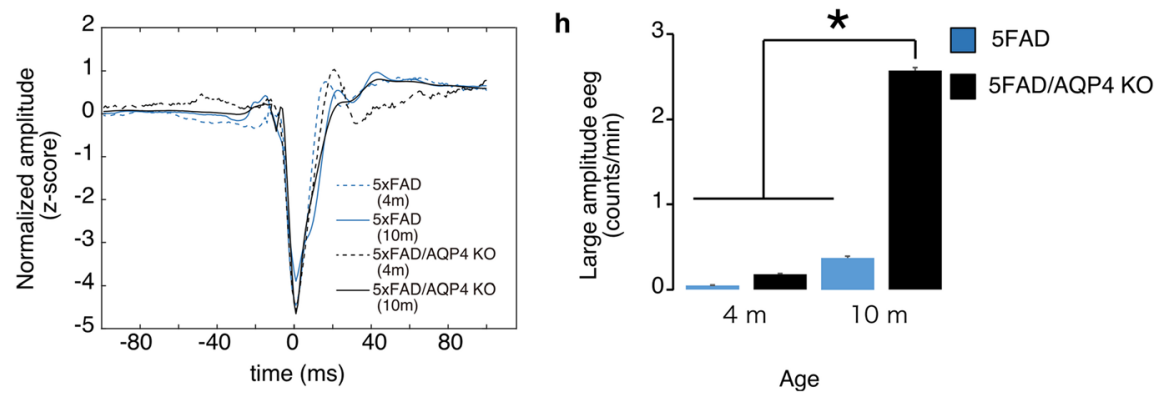

Fig. 2 Electroencephalography of 5XFAD female mice. a-f Representative electroencephalographic (EEG) traces from 4-month-old 5xFAD (a), 4month-old 5xFAD/AQP4 KO (b), 10-month-old 5xFAD (c), 10-month-old 5xFAD/AQP4 KO (d), 12-month-old wild-type (e), and 12-month-old AQP4 $\mathrm{KO}(\mathbf{f})$ mice. Red circles indicate epileptiform activity. $\mathbf{g}$ Mean traces of epileptiform spike waveforms from 5xFAD (4 months), 5xFAD/AQP4 KO (4 months), 5xFAD (10 months), and 5xFAD/AQP4 KO (10 months) mice. $\mathbf{h}$ Mean epileptiform spike counts per minute were obtained from 5xFAD ( 4 months, $n=5), 5 x F A D / A Q P 4 \mathrm{KO}(4$ months, $n=5)$, 5xFAD (10 months, $n=6)$, and 5xFAD/AQP4 KO $(10$ months, $n=10)$ mice. Values are mean \pm S.E.M. ${ }^{*}(P<0.01)$ represents significant differences of 10 -month-old $5 \times F A D / A Q P 4$ KO versus each of the other groups

mice (12 months) did not exhibit any epileptiform activity (Fig. 2e and f). Taken together, this suggests that 5xFAD mice have a predisposition to convulsions and AQP4 deficiency facilitates the onset of convulsions.

\section{Age-dependent increase in AQP4 expression around} amyloid plaques in $5 \times$ FAD mice

To understand the role of AQP4 in AD pathology, especially after the accumulation of $A \beta$ in the brain parenchyma, we 
next examined the expression of AQP4 in the 5xFAD mice. As shown in Fig. 3a, AQP4 transcription was upregulated at 24 weeks of age in both male and female $5 \times$ FAD mice. The level of the AQP4 transcript increased in an age-dependent manner, mirroring the age-dependent progression of immobility observed in AQP4 deficient 5xFAD mice. The AQP4 protein accumulated in a variety of brain regions, including the cortex, hippocampus, thalamus, and brain stem of 40week-old female 5xFAD mice (Supplemental Fig. S3a-c). Perivascular localization of AQP4 was maintained at 40 weeks of age (Fig. 3b and c, arrow heads). Aberrant expression of AQP4 was also observed around unstained regions in the $5 x F A D$ mouse brain (Fig. 3c, arrows), which were determined to be amyloid plaques via Congo red staining (Fig. $3 \mathrm{~d}$ and e) as well as 100- $\mu \mathrm{m}$ sections stained with AmyloGlo and anti-AQP4 antibody (Supplemental Fig. S4 and Supplemental Movies S3 and S4) [14, 15, 57-59].

\section{AQP4 deficiency did not significantly affect amyloid deposition or neuroinflammation in 5xFAD mice}

To explore the mechanisms by which AQP4 deficiency promotes motor dysfunction in 5xFAD mice, we then stained brain sections with an anti-A $\beta_{42}$ antibody. As shown in Fig. 4, similar plaque accumulation was observed in the
5xFAD and 5xFAD/AQP4 KO mice (Fig. 4a-h). We did not observe perivascular deposition of $\mathrm{A} \beta$ in the $5 \mathrm{xFAD}$ mice, regardless of the expression of AQP4 (Fig. 4a-h). The number of plaques in the cortical region was slightly greater in the 5xFAD mice (Fig. 4i). The average size of plaques was also determined; however, there was no significant difference between $5 \times \mathrm{xFD}$ and $5 \mathrm{xFAD} / \mathrm{AQP} 4 \mathrm{KO}$ mice although the $5 \mathrm{xFAD} / \mathrm{AQP} 4 \mathrm{KO}$ mice seemed to accumulate some large plaques with areas more than $2.2 \times 10^{3} \mu \mathrm{m}^{2}$ (Fig. 4a, b, e, and f compared to c, d, g, and h; Supplemental Fig. S5), which is consistent with a previous report [49]. Similar results were obtained in the 3D imaging of cleared hemispheres from 45-week-old female 5xFAD (Supplemental Movie S5) and 5xFAD/AQP4 KO (Supplemental Movie S6) mice, using the CUBIC method and anti-A $\beta$ (Fig. 4k; Supplemental Movies S5 and S6, green) and Amylo-Glo (Fig. 41; Supplemental Movies S5 and S6, magenta) staining followed by analysis using Imaris.

We measured insoluble $A \beta$ by ELISA up to 40 weeks of age and found that the $5 \times$ FAD mice accumulated insoluble $A \beta_{42}$ with age (Fig. $4 \mathrm{~m}$ ). $A \beta_{40}$ was also detected in the insoluble fraction, but the level of $\mathrm{A} \beta_{40}$ was 30\% of that of $A \beta_{42}$ (Fig. 4n). Consistent with the results obtained by histological analysis, there was no significant

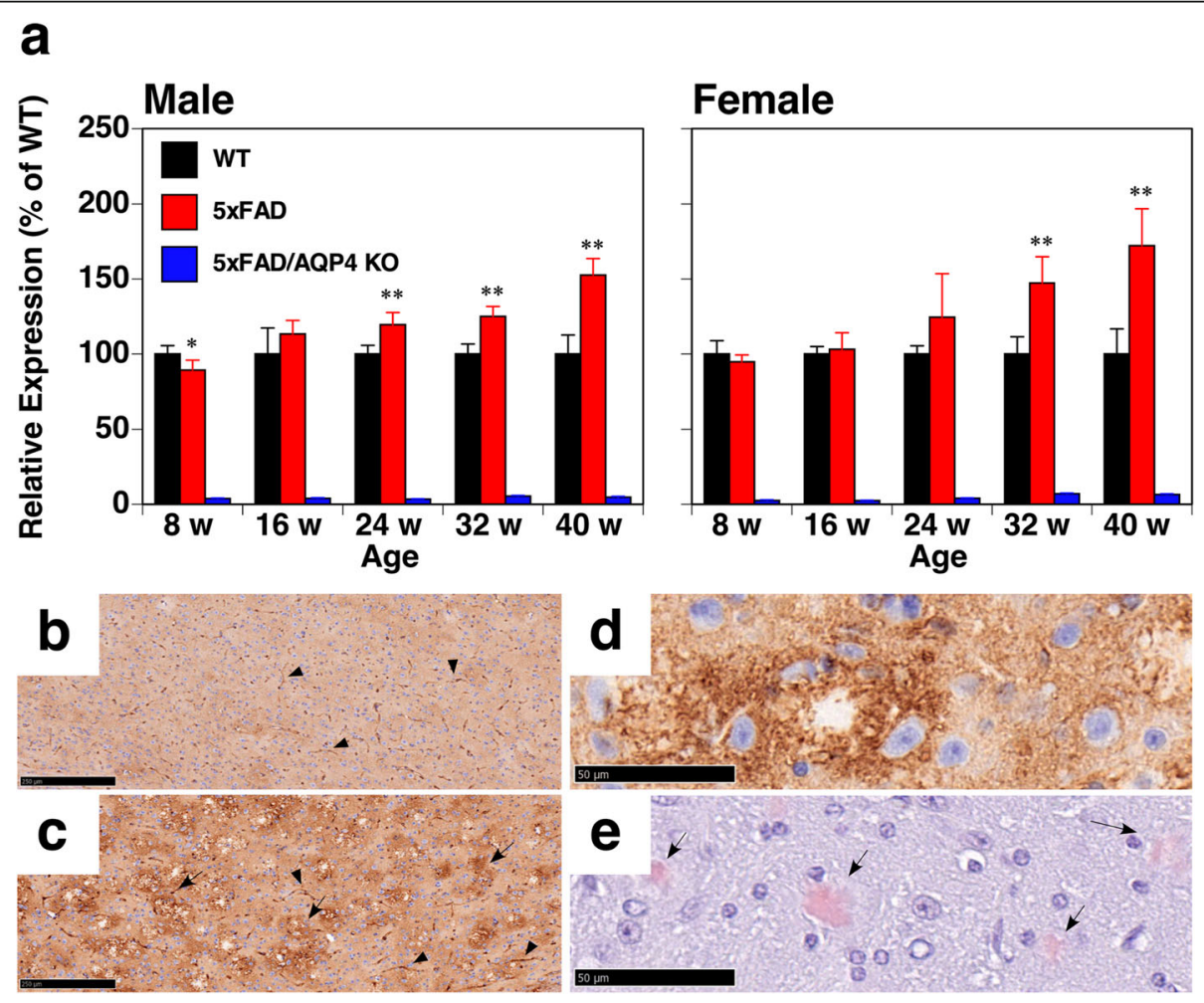

Fig. 3 Expression of AQP4 in 5xFAD mice. a QPCR analysis of brain hemispheres from wild-type (black columns), 5xFAD (red columns), and 5xFAD/AQP4 KO (blue columns) mice. Values are mean \pm S.E.M of 5-6 individuals. ${ }^{*}(P<0.01)$ and ${ }^{* *}(P<0.001)$ represent significant differences versus wild-type mice. $\mathbf{b}$ and $\mathbf{c}$ Comparison of AQP4 expression in the cortices of wild-type (b) and 5xFAD (c) mice. Perivascular staining of AQP4 is denoted by arrow heads. The expression of AQP4 around unstained spots is denoted by arrows. $\mathbf{d}$ and $\mathbf{e}$ Aberrant expression of AQP4 (d) was observed around amyloid plaques stained with Congo red (e). Scale bars $=250 \mu \mathrm{m}$ (b and c) and $50 \mu \mathrm{m}(\mathbf{d}$ and $\mathbf{e})$ 

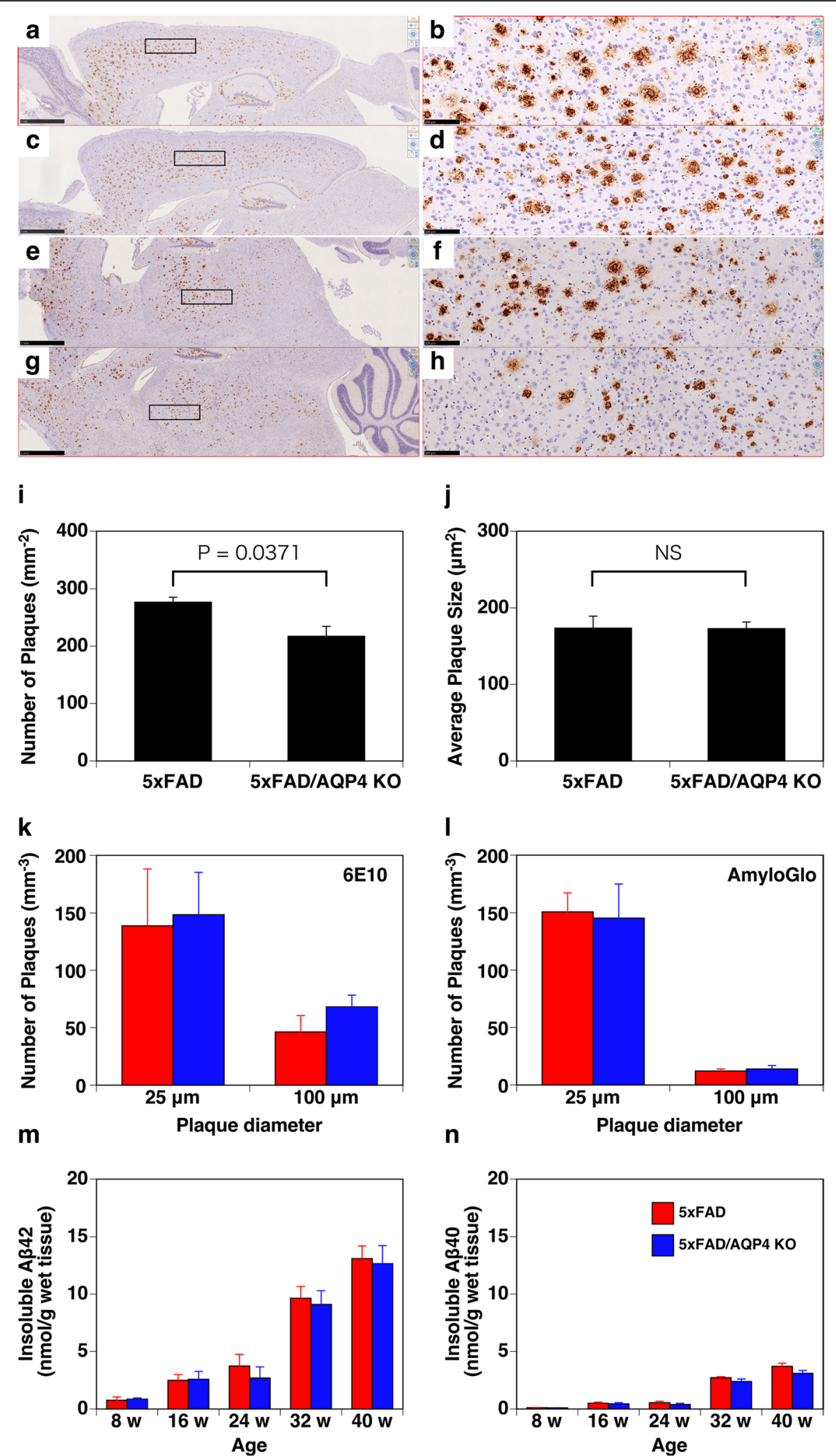

n

Plaque diameter

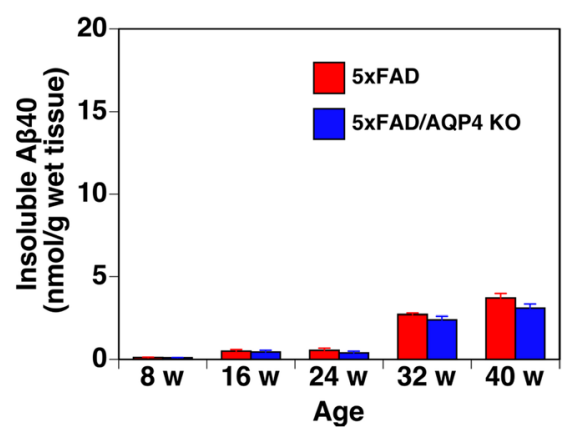

Fig. 4 (See legend on next page.) 
(See figure on previous page.)

Fig. 4 Effect of AQP4 deficiency on the deposition of $A \beta$ in parenchyma of $5 x F A D$ female mice. a-h Representative immunohistochemical images of sagittal brain sections of 40-week-old 5xFAD/AQP4 KO (a, b, e, and $\mathbf{f})$ and 5XFAD (c, d, $\mathbf{g}$, and $\mathbf{h}$ ) mice stained with an anti-A $\beta_{42}$ antibody. $\mathbf{b}, \mathbf{d}$, $\mathbf{f}$, and $\mathbf{h}$ are magnified images of $\mathbf{a}, \mathbf{c}$, e, and $\mathbf{g}$, respectively, indicated by boxes. Scale bars $=1 \mathrm{~mm}(\mathbf{a}, \mathbf{c}, \mathbf{e}$, and $\mathbf{g})$ and $100 \mu \mathrm{m}(\mathbf{b}, \mathbf{d}, \mathbf{f}$, and $\mathbf{h})$. $\mathbf{i}$ and $\mathbf{j}$ Quantification of the number of amyloid plaques and plaque size in the cortical region. The average number of plaques (i) and plaque size (j) in ten fields in two sections of cortical regions from each animal $(n=3)$, including (a) and (c), were counted using ImageJ. Values are mean \pm S.E.M of 3 individuals. $\mathbf{k}$ and $\mathbf{I}$ Quantification of the number of amyloid plaques of approximately 25 and $100 \mu m$ in diameter calculated by Imaris in the 3D imaging of cleared hemispheres from 45-week-old 5xFAD (red columns, Supplemental Movie S5) and 5xFAD/AQP4 KO (blue columns, Supplemental Movie S6) mice stained with Alexa Fluor 488-labeled 6 E10 to identify total A $\beta$ (k, green in movies) and Amylo-Glo to identify A $\beta$ fibrils (I, magenta in movies). Values are mean \pm S.E.M of 3 individuals. $\mathbf{m}$ and $\mathbf{n}$ The amounts of insoluble $A \beta_{42}(\mathbf{m})$ and $A \beta_{40}(\mathbf{n})$ extracted from the cerebral hemispheres of 5xFAD (red columns) and 5xFAD/AQP4 KO (blue columns) mice were determined by ELISA. Values are mean \pm S.E.M of 6-7 individuals

difference in insoluble $\mathrm{A} \beta$ accumulation between the $5 x F A D$ and 5xFAD/AQP4 KO mice. The expression of neprilysin was reduced in the $5 x F A D$ mice as previously reported $[9,16]$, but was not affected by the loss of AQP4 (Supplemental Fig. S6). Other enzymes responsible for $A \beta$ production and degradation were not altered in the $5 x F A D$ mice, regardless of AQP4 expression, as determined by qPCR analysis (Supplemental Fig. S6). Taken together, little effect of AQP4 deficiency on $A \beta$ deposition in the parenchyma was observed in the $5 x F A D$ mice.

In addition to insoluble $\mathrm{A} \beta$, we also measured soluble $\mathrm{A} \beta$ using ELISA. Total soluble $A \beta_{42}$ gradually increased in an age-dependent manner, and the level of soluble $\mathrm{A} \beta_{42}$ was higher in the $5 x F A D / A Q P 4 K O$ mice than the $5 x F A D$ mice between 32 and 40 weeks of age, although the difference was not statistically significant at 40 weeks of age (Fig. 5a). Since Cirrito et al. [7] suggested that soluble $A \beta$ in tissue lysates contains not only interstitial soluble $A \beta$ but also $A \beta$ loosely associated to amyloid plaques solubilized after tissue lysis, even in mild buffer, and thus it is not truly soluble and diffusible in the extracellular space. Therefore, we also measured interstitial soluble $A \beta$ in vivo using microdialysis followed by ELISA. Similarly to the soluble $A \beta$ in tissue lysates, interstitial soluble $A \beta_{42}$ in vivo in females at 33 weeks of age, but not at 25 weeks of age, tended to be higher in the 5xFAD/AQP4 KO mice than in age-matched 5xFAD mice (Fig. $5 \mathrm{c}$ and $\mathrm{d}$ ). Total soluble $\mathrm{A} \beta_{40}$ predominantly accumulated up to 16 weeks of age, and then did not drastically increase up to 40 weeks of age regardless of AQP4 expression (Fig. 5b). The interstitial soluble $A \beta_{40}$ measured in vivo in females at not 25 weeks but 33 weeks of age tended to be higher in the $5 x F A D / A Q P 4$ KO mice as seen in $A \beta_{42}$ (Fig. 5e and f). Note that the levels of soluble $A \beta_{42}$ and $A \beta_{40}$ were high in the $5 x F A D /$ AQP4 KO mice as early as 8 weeks of age, when amyloid plaques are barely detectable (Fig. $5 \mathrm{a}$ and b).

We then examined whether the loss of AQP4 affected glial responses against amyloid deposition by quantifying the transcripts of some markers of gliosis by qPCR. GFAP, a marker of reactive astrocytes, was significantly increased at 16 weeks of age and continuously increased with age both in the 5xFAD and 5xFAD/AQP4 KO mice, though there was no statistically significant difference between the groups (Fig. 6a). A homeostatic microglial marker, CX3C chemokine receptor 1 (CX3CR1) $[26,27]$, also increased with age in these mice but did not dramatically increase (Fig. 6a). This was also the case with neuroinflammatory markers such as IL1 $\beta$ and IL6 (Fig. 6a). In contrast, the expression of triggering receptor expressed on myeloid cell 2 (TREM2), an inducer of the microglial neurodegenerative phenotype [26, 27], dramatically increased between 24 and 32 weeks of age, though again there was no significant difference in microglial response between the 5xFAD and 5xFAD/ AQP4 KO mice (Fig. 6a). Histological analysis also revealed little effect of AQP4 deficiency on gliosis in the 5xFAD mice (Fig. 6b-g). We also checked the morphology of astrocytes and microglia near amyloid plaques in cortical region of 5xFAD mice using cleared $100-\mu \mathrm{m}$ sections. As far as we have observed after anti-GFAP and anti-Iba1 staining, there were no obvious differences in their morphology between 5xFAD and 5xFAD/AQP4 KO mice (Supplemental Fig. S7 and Supplemental Movies S7, S8, S9, S10). These observations support the idea that depleting AQP4 function does not affect gliosis or neuroinflammatory responses in $5 x F A D$ mice. In agreement with these results, we did not observe a difference in memory deficit between the 5xFAD and 5xFAD/AQP4 $\mathrm{KO}$ mice at 26-30 weeks of age, determined using a $\mathrm{T}$ maze test (Supplemental Fig. S1c and d).

\section{Discussion}

In the present study, we did see behavioral abnormality resulting from AQP4 deficiency, namely a reduction in nighttime activity in 5xFAD/AQP4 KO mice (Fig. 1a). This was not a direct effect of AQP4 deficiency because the symptom was not observed in AQP4 KO mice at any point during their life span. It should be noted that, although we did not detect any reduction in nighttime activity in 5xFAD mice during our analysis using Digital Vivarium $^{\mathrm{Ts}}$, we did detect a similar loss of activity in 5xFAD mice much later in their life span. This was 
a

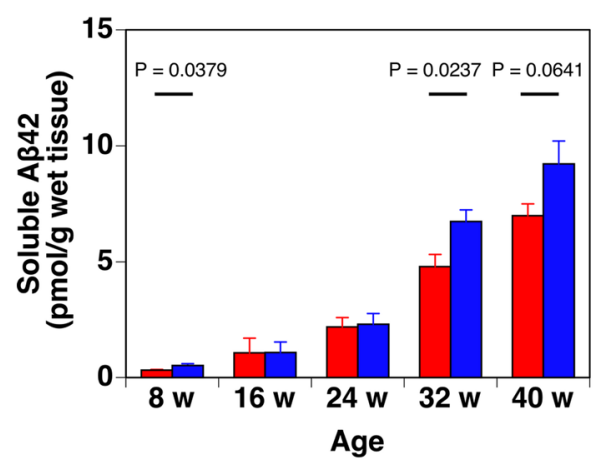

C

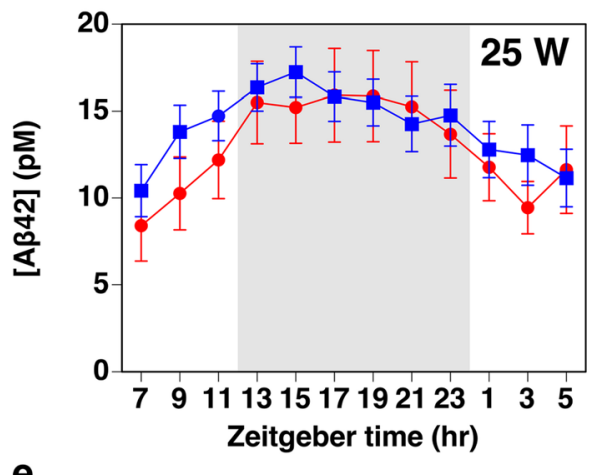

e

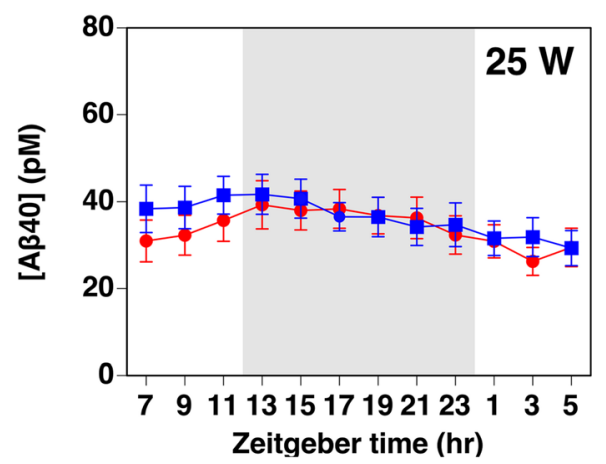

b

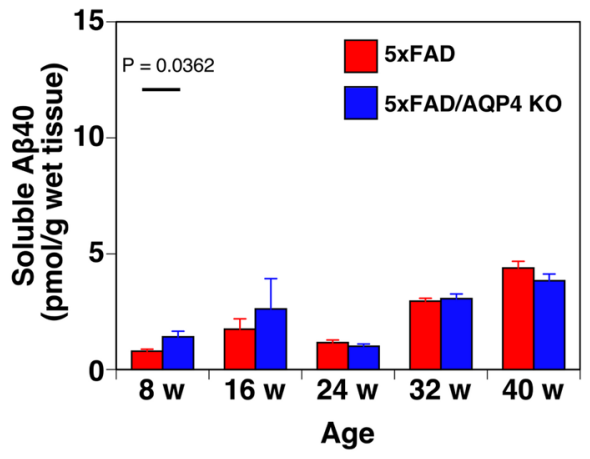

d

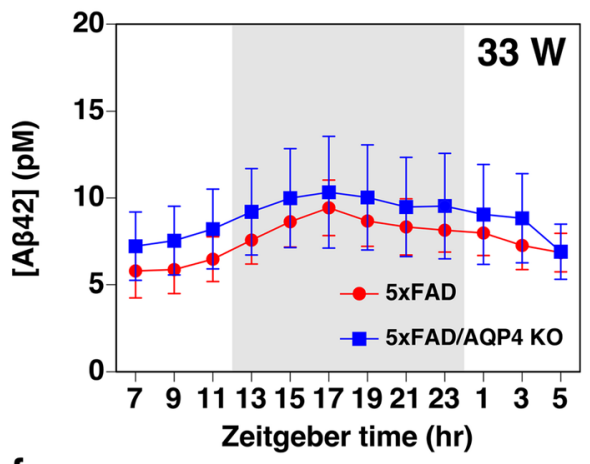

f

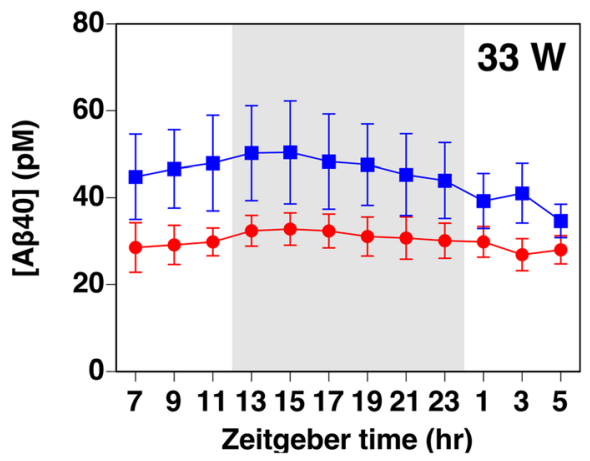

Fig. 5 Effect of AQP4 deficiency on soluble $A \beta$ levels in 5xFAD female mice. $\mathbf{a}$ and $\mathbf{b}$ The amounts of soluble $A \beta_{42}(\mathbf{a})$ and $A \beta_{40}(\mathbf{b})$ extracted from the cerebral hemispheres of 5xFAD (red columns) and 5xFAD/AQP4 KO (blue columns) mice were determined by ELISA. One individual 32week-old 5XFAD female mouse showed more than 4.0 and 7.5 times higher soluble $A \beta_{42}$ and $A \beta_{40}$ concentrations, respectively, compared with the average of the other seven individuals of the same group. Therefore, this mouse was excluded from all analyses, including insoluble $A \beta$ level shown in Fig. $4 \mathrm{~m}$ and $\mathrm{n}$. Values are mean \pm S.E.M of 6-7 individuals. c-f Time course of ISF-soluble $A \beta_{42}$ (c and $\left.\mathbf{d}\right)$ and $A \beta_{40}(\mathbf{e}$ and $\mathbf{f})$

concentrations in hippocampal region of 5xFAD (red circles) and 5xFAD/AQP4 KO (blue squares) females at 25 weeks (c and e) and 33 weeks (d and $\mathbf{f}$ ) of ages measured by ELISA of samples obtained by microdialysis. Values are mean \pm S.E.M of 6-9 individuals

consistent with previous reports [23, 41], indicating that AQP4 deficiency greatly accelerates the reduction of nighttime activity in 5xFAD mice. This behavioral abnormality is a phenomenon that occurred independently of amyloid plaque formation in the parenchyma of $5 x F A D$ mice for the following reasons. We observed little difference between the 5xFAD and 5xFAD/AQP4 KO mice in the number of amyloid plaques in the cerebral cortex as determined by immunohistochemistry and in cleared hemispheres (Fig. 4k-l). In addition, we observed age-dependent accumulation of insoluble $A \beta$; however, there was no significant effect of AQP4 deficiency up to 40 weeks of age (Fig. 4m-n). These observations indicated that in 5xFAD mice, AQP4 function is dispensable with regards to the accumulation of amyloid plaques in parenchyma. Furthermore, we did not see any 


\section{a}

GAPDH
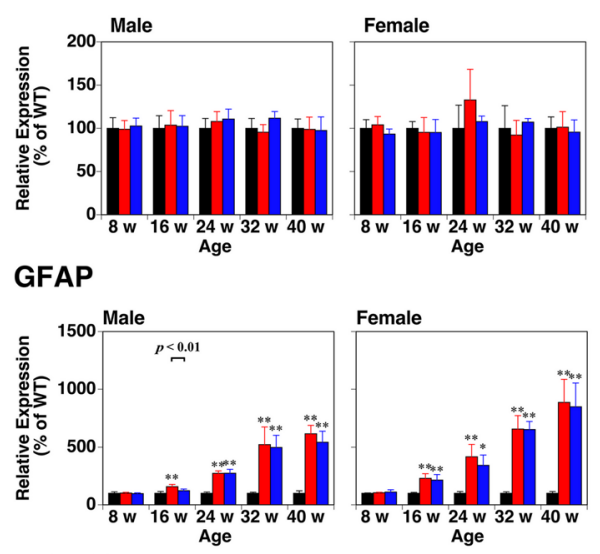

TREM2

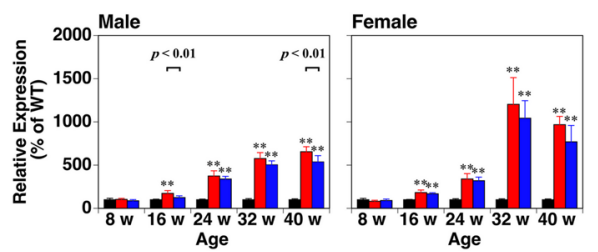

\section{CX3CR1}

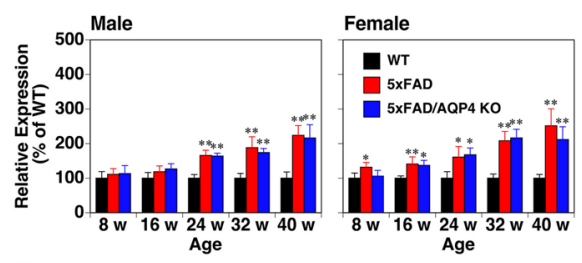

IL-1 $\beta$

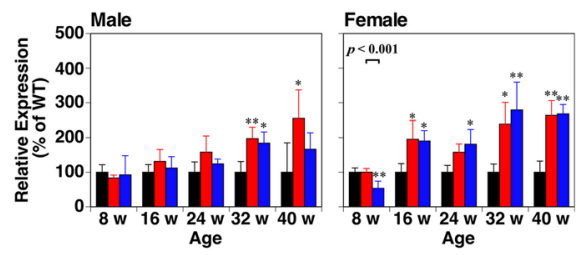

IL-6

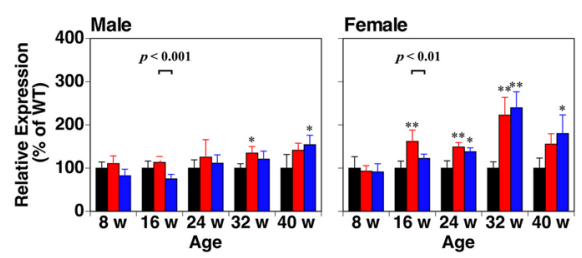

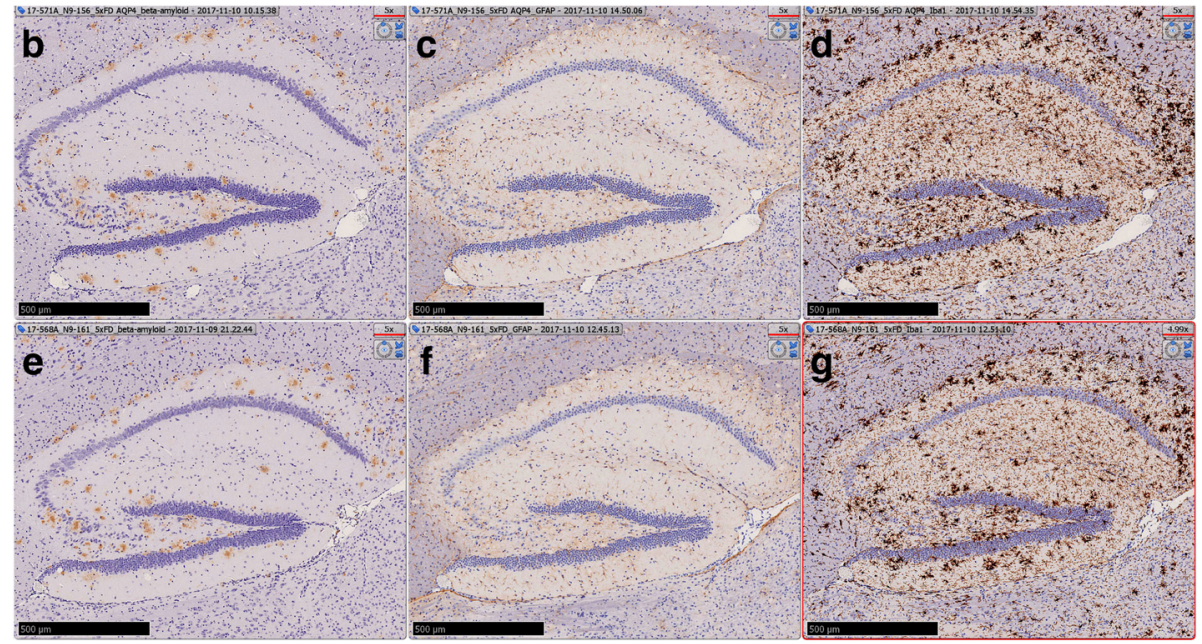

Fig. 6 Effect of AQP4 deficiency on neuroinflammatory responses in 5XFAD mice. a qPCR analysis of brain hemispheres from wild-type (black columns), 5xFAD (red columns), and 5xFAD/AQP4 KO (blue columns) mice. The level of the transcript of each gene in 5xFAD and 5xFAD/AQP4 $\mathrm{KO}$ mice was determined as the $\%$ of that of age-matched wild-type mice. Values are mean \pm S.E.M of 5-6 individuals. ${ }^{*}(P<0.01)$ and ${ }^{* *}(P<0.001)$ represent significant differences versus wild-type mice. The primers used are listed in Supplemental Table S2. b-g Immunostaining of A $(\mathbf{b}$ and e), GFAP (c and $\mathbf{f}$ ), and Iba1 (d and $\mathbf{g}$ ) in the hippocampal region of 5xFAD/AQP4 KO (b-d) and 5xFAD (e-g) mice. Scale bars $=500 \mu \mathrm{m}$

differences between 5xFAD and 5xFAD/AQP4 KO mice in the age-dependent increase of gliosis or subsequent neuroinflammatory response (Fig. 6). This result strongly suggests that not only the accumulation of amyloid plaques, but also glial responses, which may be the direct response of astrocytes and microglia against the amyloid plaques and which include neuroinflammation, are not directly implicated in the reduction in nighttime activity in AQP4-deficient 5xFAD mice.
Recently, $\mathrm{Xu}$ et al. have demonstrated the role of AQP4 in A $\beta$ clearance in APP/PS1 mice [57]. Deleting AQP4 from APP/PS1 [21] mice resulted in increased accumulation of amyloid both as plaques in parenchyma and as cerebral amyloid angiopathy (CAA) around blood vessels, as well as increased soluble A $\beta$ levels [57]. These results indicate that AQP4 is implicated in $A \beta$ clearance, probably via the interstitial fluid bulk-flow clearance system [52] in APP/ 
PS1 mice. In contrast, as described above, we did not see any difference in amyloid plaques/insoluble $A \beta$ accumulation between 5xFAD and 5xFAD/AQP4 KO mice. This dissimilarity is attributable to the difference in contribution of interstitial fluid bulk-flow clearance [52] to $A \beta$ clearance from parenchyma between APP/PS1 and 5xFAD mice. In APP/PS1 mice, production of $A \beta_{40}$ is relatively high and formation of amyloid plaques is relatively slow (as early as 6 months of age as compared with as early as 2 months of age in 5xFAD) [11, 22]. In addition, age-dependent CAA was observed in APP/PS1 mice by 6 months of age [11]. Therefore, interstitial fluid bulk-flow likely has a significant role in A $\beta$ clearance $[5,54]$ in APP/ PS1 mice. However, in 5xFAD mice, amyloid plaques appear at as early as 2 months of age [40]. These plaques continuously incorporate $A \beta$ due to the production of high levels of $A \beta_{42}$ [20], likely in cooperation with reduced neprilysin expression (Supplemental Fig. S6) $[9,16]$. Importantly, CAA never occurs in 5xFAD mice [56], and consistent with this report, we did not observe any accumulation of $A \beta$ around blood vessels in the $5 \mathrm{xFAD}$ mice up to 40 weeks of age, regardless of AQP4 expression (Fig. 4a-h and Supplemental Movies S5 and S6). These observations strongly suggest that the interstitial fluid bulk-flow clearance system hardly contributes to $\mathrm{A} \beta$ clearance in 5xFAD mice. Considering the difference between the two models as well as our observations, we conclude that AQP4 function is dispensable in the age-dependent accumulation of amyloid plaques under the conditions in which the interstitial fluid bulk-flow clearance system fails to work for $A \beta$ clearance. This also means that interstitial fluid bulk-flow is the only mechanism for $A \beta$ clearance in which AQP4 is involved. Thus, using $5 \mathrm{xFAD}$ mice, we were able to assess the implications of AQP4 after the accumulation of amyloid plaques in the parenchyma.

Strikingly, our 24-h observation of the behavior of individual mice between 20 and 36 weeks of age using Digital Vivarium $^{\mathrm{Tx}}$ revealed that all 11 5xFAD/AQP4 KO mice experienced convulsions at least once. These convulsions were observed only after the reduction in nighttime movement had occurred (Fig. 1). The comorbidity of $\mathrm{AD}$ and neuronal hyperactivity or seizures has been suggested in previous studies on $A D$ patients and transgenic $\mathrm{AD}$ mouse models [2]. Other AD models also exhibit convulsions [24, 30, 55] and spontaneous epileptiform discharges [37, 42]. Multiple reports have demonstrated that spontaneous epileptiform activity [1] and a susceptibility to pharmacologically induced seizures $[1,8,25,55]$ were detected before plaque deposition or memory deficits. Therefore, the formation of amyloid plaques does not seem to be a trigger for inducing epileptiform activity. Given previous studies, the epileptiform discharges observed in the early stages in $5 x F A D$ may be an effect of the overexpression of human amyloid precursor protein (APP) from the transgene [3, 4]. Our results, however, strongly suggest that there is a link between the aggravation of epileptiform neuronal activity/convulsions and the observed changes in behavior after 28 weeks of age. It seems likely that factors other than the overexpression of human APP are involved in these symptoms and that a loss of AQP4 critically deteriorates these processes. Previous studies have demonstrated an increased risk of seizures in $\mathrm{AD}$ patients [2]. In addition, EEG abnormalities have also been observed in non-epileptic $\mathrm{AD}$ patients [2]. Since the onset of seizures follows cognitive impairment, it is suggested that seizures are consequences of $\mathrm{AD}$ pathology. In contrast, Vossel et al. suggested that epileptiform activity may contribute to the development of cognitive decline in AD patients and is not just a marker of the end stage of disease $[2,53]$. The $5 \mathrm{xFAD} / \mathrm{AQP} 4 \mathrm{KO}$ mice model can be a good tool for identifying the relationship between $\mathrm{AD}$ and epileptiform activity. For example, it can be used to examine epileptiform activity modulation by antiepileptic drugs and their effect on the accumulation of amyloid plaque, subsequent neuroinflammation, and memory deficit.

It is still unclear why the effects of AQP4 deficiency first appear as late as 28 weeks of age in this model. One possible reason is that the ability of amyloid plaques in the parenchyma to incorporate soluble $A \beta$ is not saturated until around 28 weeks of age in 5xFAD mice. No matter how much AQP4 is implicated in the interstitial fluid bulk-flow clearance system [52], AQP4 function would not be required for $A \beta$ clearance until this parenchymal storage system was saturated because it is highly likely that the interstitial fluid bulk-flow clearance system [52] contributes little to $A \beta$ clearance in $5 x F A D$ mice [56]. Interestingly, we detected an elevated level of soluble $\mathrm{A} \beta$ in 5xFAD/ AQP4 KO mice older than 24 weeks (Fig. 5). We saw that transcription of AQP4 was upregulated starting from 24 weeks of age, and it increased in an agedependent manner (Fig. 3). The accumulation of AQP4 protein was found around amyloid plaques in 5xFAD mice (Fig. 3). These observations suggest that the ectopic expression of AQP4 is required for the maintenance of soluble $A \beta$ level in parenchyma. It should be noted that we also detected an elevated level of soluble $\mathrm{A} \beta$ in $5 \mathrm{xFAD} / \mathrm{AQP} 4 \mathrm{KO}$ mice aged 8 weeks (Fig. 5), which is a stage in which amyloid plaques are barely detectable. At this stage, the amount of amyloid plaques might not be high enough to 
capture the produced $A \beta$, supporting the idea that when the capacity of plaques to incorporate $A \beta$ is not high enough, soluble $A \beta$ level is elevated. Thus, an elevated level of soluble $A \beta$ is one potential factor responsible for the accelerated loss of mobility and the aggravation of epileptiform neuronal activity/convulsions observed in 5xFAD/AQP4 $\mathrm{KO}$ mice. Cirrito et al. suggested that soluble $A \beta$ in tissue lysates contains not only interstitial soluble $A \beta$ but also $A \beta$ loosely associated to amyloid plaques solubilized after tissue lysis, even in mild buffer, and thus, soluble $A \beta$ in tissue lysates is not truly soluble and diffusible in the extracellular space [7]. We detected increased level of interstitial $\mathrm{A} \beta$ in $5 \mathrm{xFAD} / \mathrm{AQP} 4 \mathrm{KO}$ females older than 25 weeks old as compared with agematched 5xFAD females, although there was no significant difference between these groups. Insoluble $A \beta$ levels in tissue lysates in these two groups are almost the same. Nevertheless, Soluble A $\beta$ levels in tissue lysates were high in $5 x F A D / A Q P 4 \mathrm{KO}$ females. Therefore, it is possible that in $5 \times \mathrm{xAD} / \mathrm{AQP} 4 \mathrm{KO}$ females, the increased levels of soluble $A \beta$ reflect increase in the amount of $A \beta$ loosely associated to amyloid plaques because of lack of AQP4 solubilized after tissue lysis, which is consistent with Smith et al. [49]. It is also possible that the clearance of neurotoxic substances derived from degenerating neurons, including lipids, nucleotides, proteins, neurotransmitters, and ions, is impaired in 5xFAD/AQP4 KO mice. The expression of TREM2 was upregulated from 32 weeks of age (Fig. 6). Therefore, it is possible that neurodegeneration progressively occurred at this stage. Further investigations are required to elucidate the role of AQP4 in the abnormal behavior and aggravation of epileptiform neuronal activity/convulsions, which occur after amyloid plaque deposition and neuroinflammation.

\section{Conclusions}

Using 5xFAD mice, we examined the effects of deleting $\mathrm{AQP} 4$ on the pathogenesis of $\mathrm{AD}$ after the accumulation of amyloid plaques. AQP4 was found to not be directly involved in gliosis, neuroinflammation in response to amyloid plaque deposition, or cognitive function determined by $\mathrm{T}$-maze test. However, we found a neuroprotective function of AQP4 against other age-dependent deterioration of neuronal function progressing independently of amyloid plaque deposition and following gliosis, which include a reduction in nighttime movement associated with epileptiform activity of the brain and convulsions. Our results provide an important perspective for developing new diagnostic methods and treatments for Alzheimer's disease.

\section{Supplementary information}

Supplementary information accompanies this paper at https://doi.org/10. 1186/s40478-020-00936-3.
Additional file 1. Supplemental Movie S1.
Additional file 2. Supplemental Movie S2.
Additional file 3. Supplemental Movie S3.
Additional file 4. Supplemental Movie $\$ 4$.
Additional file 5. Supplemental Movie S5.
Additional file 6. Supplemental Movie S6.
Additional file 7. Supplemental Movie S7.
Additional file 8. Supplemental Movie S8.
Additional file 9. Supplemental Movie S9.
Additional file 10. Supplemental Movie S10.
Additional file 11. Supplemental Figures.
Additional file 12. Supplemental Tables.

\section{Abbreviations}

A $\beta$ : Amyloid $\beta$; AD: Alzheimer's disease; APP: Amyloid precursor protein; AQP4: Aquaporin-4; CAA: Cerebral amyloid angiopathy; CNS: Central nervous system; CSF: Cerebrospinal fluid; CUBIC: Clear, Unobstructed Brain/Body Imaging Cocktails; CX3CR1: CX3C chemokine receptor 1; EAE: Experimental autoimmune encephalomyelitis; EEG: Electroencephalography/ electroencephalogram; FAD: Familial Alzheimer's disease; GFAP: Glial fibrillary acidic protein; Iba1: Ionized calcium binding adaptor molecule 1; ISF: Interstitial fluid; KO: Knockout; LPS: Lipopolysaccharide;

PFA: Paraformaldehyde; PS1: Presenilin 1; TREM2: triggering receptor expressed on myeloid cell 2

\section{Acknowledgments}

The authors thank Dr. Robert Vassar for providing 5xFAD mice; Dr. Jordan Mechanic for instruction on analysis using Digital Vivarium ${ }^{\text {TM}}$; Dr. Akira Sato for instruction on 3D imaging and analysis of cleared brains using Lightsheet Z.1 and Imaris; Dr. Sangram S. Sisodia for helpful discussions and comments on the manuscript; Collaborative Research Resources, School of Medicine, Keio University for technical assistance; and all members of the Department of Pharmacology, School of Medicine, Keio University for cooperation. Behavioral analysis was carried out at the Institute for Comprehensive Medical Science, Fujita Health University, by the Joint Usage/Research Center for Genes, Brain and Behavior, which is accredited by MEXT.

\section{Authors' contributions}

Y.A., S.H., T.Y., T.H., K.Ya., H.M., M.Mi., K.F.T., T.M., T.I., J.H., T.N., and M.Y. conceived, designed and coordinated the study. N.I., S.H., M.Mu., and T.T. performed behavioral tests. K.Yo. performed EEG. K.K. and J.H. performed the immunohistochemistry. M.G. performed in vitro fertilization to prepare 5xFAD mice. G.W. performed clearing mouse brains, immunofluorescent staining, and collecting images. N.I. performed microdialysis. K.M., T.H., K.Ya., and Y.A. measured $A \beta$ concentration. Y.A. performed RNA extraction from the brains and qPCR. Y.A., T.S., and T.N. analyzed the data. Y.A., K.Yo, S.H., K.F.T, T.N., and M.Y. wrote the first draft. All the authors read and approved the final manuscript.

\section{Funding}

This work was supported by grants from the Japan Society for the Promotion of Science Grant-in-Aid for Challenging Exploratory Research (2567025) (Y.A.), Grant-in-Aid for Challenging Research (Exploratory) (17 K19637) (Y.A.), and Grant-in-Aid for Scientific Research (B) (18H02606) (M.Y.); from Suntory Global Innovation Center Ltd. program "Water Channeling Life" (M.Y.), from Keio University Program for the Advancement of Research in Core Projects under Keio University's Longevity Initiative (M.Y.); and from the Ministry of Education, Science, Sports and Culture of Japan (MEXT) Grant-inAid for Scientific Research on Innovative Areas "Platform of Advanced Animal Model Support" (16H06276) (T.M.). 


\section{Availability of data and materials}

The datasets used and/or analyzed during the current study available from the authors on reasonable request.

\section{Ethics approval and consent to participate}

This article does not contain any studies with human participants performed by any of the authors.

All animal experiments were performed according to the Act on Welfare and Management of Animals and related Japanese governmental guidelines and regulations. Those in Keio University, in Sophia University, and Fujita Health University were approved by Institutional Animal Care and Use Committee at Keio University (09084-11 and 16076-2), at Sophia University (2016-19), and at Fujita Health University (AP16016), respectively.

\section{Consent for publication}

Not applicable.

\section{Competing interests}

Masato Yasui has received funding for the research from Suntory Global Innovation Center Ltd.

The other authors declare that they have no competing interests.

\section{Author details}

'Department of Pharmacology, Keio University School of Medicine, 35 Shinanomachi, Shinjuku-ku, Tokyo 160-8582, Japan. ${ }^{2}$ Center for Water Biology \& Medicine, Keio University Global Research Institute, Mita, Tokyo 108-8345, Japan. ${ }^{3}$ Department of Information and Communication Sciences, Faculty of Science and Technology, Sophia University, 7-1 Kioi-cho, Chiyoda-ku, Tokyo 102-8554, Japan. ${ }^{4}$ Department of Neuropsychiatry, Keio University School of Medicine, 35 Shinanomachi, Sinjuku-ku, Tokyo 160-8582, Japan. ${ }^{5}$ Department of Neuropathology, Graduate School of Medicine, University of Tokyo, 7-3-1 Hongo, Bunkyo-ku, Tokyo 113-0033, Japan. ${ }^{6}$ Division of System Medical Science, Institute for Comprehensive Medical Science, Fujita Health University, 1-98, Dengakugakubo, Kutsukake-cho, Toyoake, Aichi 470-1192, Japan. ${ }^{7}$ Central Institute for Experimental Animals (CIEA), 3-25-12 Tonomachi, Kawasaki-ku, Kawasaki 210-0821, Japan. ${ }^{8}$ Division of Pharmacology, Faculty of Pharmacy, Keio University, 1-5-30, Shibakoen, Minato-ku, Tokyo 105-8512, Japan.

\section{Received: 23 January 2020 Accepted: 21 April 2020} Published online: 12 May 2020

\section{References}

1. Bezzina C, Verret L, Juan C, Remaud J, Halley H, Rampon C et al (2015) Early onset of hypersynchronous network activity and expression of a marker of chronic seizures in the Tg2576 mouse model of Alzheimer's disease. PLoS One 10:e0119910 https://doi.org/10.1371/journal.pone.0119910

2. Born HA (2015) Seizures in Alzheimer's disease. Neuroscience 286:251-263 https://doi.org/10.1016/j.neuroscience.2014.11.051

3. Born HA, Kim JY, Savjani RR, Das P, Dabaghian YA, Guo Q et al (2014) Genetic suppression of transgenic APP rescues hypersynchronous network activity in a mouse model of Alzeimer's disease. J Neurosci 34:3826-3840 https://doi.org/10.1523/JNEUROSCI.5171-13.2014

4. Brown R, Lam AD, Gonzalez-Sulser A, Ying A, Jones M, Chou RC et al (2018) Circadian and brain state modulation of network hyperexcitability in Alzheimer's disease. eNeuro 5:e0426-e0417 https://doi.org/10.1523/ENEURO.0426-17.2018

5. Carare RO, Bernardes-Silva M, Newman TA, Page AM, Nicoll JA, Perry VH et al (2008) Solutes, but not cells, drain from the brain parenchyma along basement membranes of capillaries and arteries: significance for cerebral amyloid angiopathy and neuroimmunology. Neuropathol Appl Neurobiol 34:131-144 https://doi.org/10.1111/j.1365-2990.2007.00926.x

6. Chun H, Marriott I, Lee CJ, Cho H (2018) Elucidating the interactive roles of glia in Alzheimer's disease using established and newly developed experimental models. Front Neurol 9:797 https://doi.org/10.3389/fneur.2018.00797

7. Cirrito JR, May PC, O'Dell MA, Taylor JW, Parsadanian M, Cramer JW et al (2003) In vivo assessment of brain interstitial fluid with microdialysis reveals plaque-associated changes in amyloid- $\beta$ metabolism and half-life. J Neurosci 23:8844-8853 https://doi.org/10.1523/JNEUROSCI.23-26-08844.2003

8. Del Vecchio RA, Gold LH, Novick SJ, Wong G, Hyde LA (2004) Increased seizure threshold and severity in young transgenic CRND8 mice. Neurosci Lett 367:164-167 https://doi.org/10.1016/j.neulet.2004.05.107
9. Devi L, Ohno M (2013) Mechanisms that lessen benefits of $\beta$-secretase reduction in a mouse model of Alzheimer's disease. Transl Psychiatry 3:e284 https://doi.org/10.1038/tp.2013.59

10. Eidsvaag VA, Enger R, Hansson HA, Eide PK, Nagelhus EA (2017) Human and mouse cortical astrocytes differ in aquaporin-4 polarization toward microvessels. Glia 65:964-973 https://doi.org/10.1002/glia.23138

11. Garcia-Alloza M, Robbins EM, Zhang-Nunes SX, Purcell SM, Betensky RA, Raju S et al (2006) Characterization of amyloid deposition in the APPswe/PS1 dE9 mouse model of Alzheimer disease. Neurobiol Dis 24:516-524 https://doi. org/10.1016/j.nbd.2006.08.017

12. Hanazawa A, Ito R, Katano I, Kawai K, Goto M, Suemizu H et al (2018) Generation of human immunosuppressive myeloid cell populations in human interleukin-6 transgenic NOG mice. Front Immunol 29:152 https:// doi.org/10.3389/fimmu.2018.00152

13. Hashimoto T, Wakabayashi T, Watanabe A, Kowa H, Hosoda R, Nakamura A et al (2002) CLAC: a novel Alzheimer amyloid plaque component derived from a transmembrane precursor, CLAC-P/collagen type XXV. EMBO J 21: 1524-1534 https://doi.org/10.1093/emboj/21.7.1524

14. Hoshi A, Yamamoto T, Shimizu K, Ugawa Y, Nishizawa M, Takahashi H et al (2012) Characteristics of aquaporin expression surrounding senile plaques and cerebral amyloid angiopathy in Alzheimer disease. J Neuropathol Exp Neurol 71:750-759 https://doi.org/10.1097/NEN.0b013e3182632566

15. Hoshi A, Tsunoda A, Yamamoto T, Tada M, Kakita A, Ugawa Y (2018) Altered expression of glutamate transporter-1 and water channel protein aquaporin-4 in human temporal cortex with Alzheimer's disease. Neuropathol Appl Neurobiol 44:628-638 https://doi.org/10.1111/nan.12475

16. Hüttenrauch $M$, Walter S, Kaufmann M, Weggen S, Wirths $O$ (2017) Limited effects of prolonged environmental enrichment on the pathology of 5xFAD mice. Mol Neurobiol 54:6542-6555 https://doi.org/10.1007/s12035-016-0167-x

17. Ikeshima-Kataoka H, Abe Y, Abe T, Yasui M (2013) Immunological function of aquaporin-4 in stab-wounded mouse brain in concert with a proinflammatory cytokine inducer, osteopontin. Mol Cell Neurosci 56:65-75 https://doi.org/10.1016/j.mcn.2013.02.002

18. Iliff JJ, Wang M, Liao Y, Plogg BA, Peng W, Gundersen GA et al (2012) A paravascular pathway facilitates CSF flow through the brain parenchyma and the clearance of interstitial solutes, including amyloid $\beta$. Sci Transl Med 4:147ra111 https://doi.org/10.1126/scitranslmed.3003748

19. Itagaki S, McGeer PL, Akiyama H, Zhu S, Selkoe D (1989) Relationship of microglia and astrocytes to amyloid deposits of Alzheimer disease. J Neuroimmunol 24:173-182 https://doi.org/10.1016/0165-5728(89)90115-X

20. Iwatsubo T, Odaka A, Suzuki N, Mizusawa H, Nukina N, Ihara Y (1994) Visualization of A beta $42(43)$ and A beta 40 in senile plaques with end-specific A beta monoclonals: evidence that an initially deposited species is A beta 42(43). Neuron 13:45-53 https://doi.org/10.1016/0896-6273(94)90458-8

21. Jankowsky JL, Slunt HH, Ratovitski T, Jenkins NA, Copeland NG, Borchelt DR (2001) Co-expression of multiple transgenes in mouse CNS: a comparison of strategies. Biomol Eng 17:157-165 https://doi.org/10.1016/S13890344(01)00067-3

22. Jankowsky JL, Fadale DJ, Anderson J, Xu GM, Gonzales V, Jenkins NA et al (2004) Mutant presenilins specifically elevate the levels of the 42 residue beta-amyloid peptide in vivo: evidence for augmentation of a 42 -specific gamma secretase. Hum Mol Genet 13:159-170 https://doi.org/10.1093/hmg/ ddh019

23. Jawhar S, Trawicka A, Jenneckens C, Bayer TA, Wirths O (2012) Motor deficits, neuron loss, and reduced anxiety coinciding with axonal degeneration and intraneuronal A $\beta$ aggregation in the 5XFAD mouse model of Alzheimer's disease. Neurobiol Aging 33:196.e29-196.e40 https:// doi.org/10.1016/j.neurobiolaging.2010.05.027

24. Jolas T, Zhang XS, Zhang Q, Wong G, Del Vecchio R, Gold L et al (2002) Long-term potentiation is increased in the CA1 area of the hippocampus of APP (swe/ind) CRND8 mice. Neurobiol Dis 11:394-409 https://doi.org/10. 1006/nbdi.2002.0557

25. Kazim SF, Chuang SC, Zhao W, Wong RK, Bianchi R, lqbal K (2017) Earlyonset network hyperexcitability in presymptomatic Alzheimer's disease transgenic mice is suppressed by passive immunization with anti-human APP/A 3 antibody and by mGluR5 blockade. Front Aging Neurosci 9:71 https://doi.org/10.3389/fnagi.2017.00071

26. Keren-Shaul H, Spinrad A, Weiner A, Matcovitch-Natan O, Dvir-Szternfeld R, Ulland TK et al (2017) A unique microglia type associated with restricting development of Alzheimer's disease. Cell 169:1276-1290 https://doi.org/10. 1016/j.cell.2017.05.018 
27. Krasemann S, Madore C, Cialic R, Baufeld C, Calcagno N, El Fatimy R et al (2017) The TREM2-APOE pathway drives the transcriptional phenotype of dysfunctional microglia in neurodegenerative diseases. Immunity 47:566581 https://doi.org/10.1016/j.immuni.2017.08.008

28. Kress BT, Iliff JJ, Xia M, Wang M, Wei HS, Zeppenfeld D et al (2014) Impairment of paravascular clearance pathways in the aging brain. Ann Neurol 76:845-861 https://doi.org/10.1002/ana.24271

29. Kubota SI, Takahashi K, Nishida J, Morishita Y, Ehata S, Tainaka K et al (2017) Whole-body profiling of cancer metastasis with single-cell resolution. Cell Rep 20:236-250 https://doi.org/10.1016/j.celrep.2017.06.010

30. Lalonde R, Dumont M, Staufenbiel M, Strazielle C (2005) Neurobehavioral characterization of APP23 transgenic mice with the SHIRPA primary screen. Behav Brain Res 157:91-98 https://doi.org/10.1016/j.bbr.2004.06.020

31. Li L, Zhang H, Verkman AS (2009) Greatly attenuated experimental autoimmune encephalomyelitis in aquaporin-4 knockout mice. BMC Neurosci 10:94 https://doi.org/10.1186/1471-2202-10-94

32. Li L, Zhang H, Varrin-Doyer M, Zamvil SS, Verkman AS (2011) Proinflammatory role of aquaporin-4 in autoimmune neuroinflammation. FASEB J 25:1556-1566 https://doi.org/10.1096/fj.10-177279

33. Liang F, Luo C, Xu G, Su F, He X, Long S et al (2015) Deletion of aquaporin4 is neuroprotective during the acute stage of micro traumatic brain injury in mice. Neurosci Lett 598:29-35 https://doi.org/10.1016/j.neulet.2015.05.006

34. Liang R, Yong S, Huang X, Kong H, Hu G, Fan Y (2016) Aquaporin-4 mediates the suppressive effect of lipopolysaccharide on hippocampal neurogenesis. Neuroimmunomodulation 23:309-317 https://doi.org/10. $1159 / 000467141$

35. Lim MA, Defensor EB, Mechanic JA, Shah PP, Jaime EA, Roberts CR et al (2019) Retrospective analysis of the effects of identification procedures and cage changing by using data from automated, continuous monitoring. J Am Assoc Lab Anim Sci 58:126-141 https://doi.org/10.30802/AALASJAALAS-18-000056

36. Mestre H, Hablitz LM, Xavier AL, Feng W, Zou W, Pu T et al (2018) Aquaporin-4-dependent glymphatic solute transport in the rodent brain. eLife 7:e40070 https://doi.org/10.7554/eLife.40070.001

37. Minkeviciene R, Rheims S, Dobszay MB, Zilberter M, Hartikainen J, Fülöp L et al (2009) Amyloid $\beta$-induced neuronal hyperexcitability triggers progressive epilepsy. J Neurosci 29:3453-3462 https://doi.org/10.1523/ JNEUROSCI.5215-08.2009

38. Nagelhus EA, Ottersen OP (2013) Physiological roles of aquaporin-4 in brain. Physiol Rev 93:1543-1562 https://doi.org/10.1152/physrev.00011.2013

39. Newcombe EA, Camats-Perna J, Silva ML, Valmas N, Huat TJ, Medeiros R (2018) Inflammation: the link between comorbidities, genetics, and Alzheimer's disease. J Neuroinflammation 15:276 https://doi.org/10.1186/ s12974-018-1313-3

40. Oakley H, Cole SL, Logan S, Maus E, Shao P, Craft J et al (2006) Intraneuronal $\beta$-amyloid aggregates, neurodegeneration, and neuron loss in transgenic mice with five familial Alzheimer's disease mutations: potential factors in amyloid plaque formation. J Neurosci 4:10129-10140 https://doi.org/10. 1523/JNEUROSCI.1202-06.2006

41. O'Leary TP, Mantolino HM, Stover KR, Brown RE (2018) Age-related deterioration of motor function in male and female 5xFAD mice from 3 to 16 months of age. Genes Brain Behav 13:e12538 https://doi.org/10.1111/ gbb.12538

42. Palop JJ, Chin J, Roberson ED, Wang J, Thwin MT, Bien-Ly N et al (2007) Aberrant excitatory neuronal activity and compensatory remodeling of inhibitory hippocampal circuits in mouse models of Alzheimer's disease. Neuron 55:697-711 https://doi.org/10.1016/j.neuron.2007.07.025

43. Paxinos G, Franklin KBJ $(2008,2012)$ The mouse brain in stereotaxic coordinates. 3rd and 4th ed. Cambridge: Academic Press.

44. Saadoun S, Papadopoulos MC, Watanabe H, Yan D, Manley GT, Verkman AS (2005) Involvement of aquaporin-4 in astroglial cell migration and glial scar formation. J Cell Sci 118:5691-5698 https://doi.org/10.1242/jcs.02680

45. Saito T, Saido TC (2018) Neuroinflammation in mouse models of Alzheimer's disease. Clin Exp Neuroimmunol 9:211-218 https://doi.org/ 10.1111/cen3.12475

46. Shi WZ, Zhao CZ, Zhao B, Zheng XL, Fang SH, Lu YB et al (2012) Aquaporin4 deficiency attenuates acute lesions but aggravates delayed lesion and microgliosis after cryoinjury to mouse brain. Neurosci Bull 28:61-68 https:// doi.org/10.1007/s12264-012-1063-7
47. Shi WZ, Qi LL, Fang SH, Lu YB, Zhang WP, Wei EQ (2012) Aggravated chronic brain injury after focal cerebral ischemia in aquaporin-4-deficient mice. Neurosci Lett 520:121-125 https://doi.org/10.1016/j.neulet.2012.05.052

48. Shoji H, Miyakawa T (2019) Age-related behavioral changes from young to old age in male mice of a C57BL/6J strain maintained under a genetic stability program. Neuropsychopharmacol Rep 38:100-118 https://doi.org/ 10.1002/npr2.12052

49. Smith AJ, Duan T, Verkman AS (2019) Aquaporin-4 reduces neuropathology in a mouse model of Alzheimer's disease by remodeling peri-plaque astrocyte structure. Acta Neuropathol Commun 7:74 https://doi.org/10.1186/ s40478-019-0728-0

50. Sun H, Liang R, Yang B, Zhou Y, Liu M, Fang F et al (2016) Aquaporin-4 mediates communication between astrocyte and microglia: implications of neuroinflammation in experimental Parkinson's disease. Neuroscience 317: 65-75 https://doi.org/10.1016/j.neuroscience.2016.01.003

51. Susaki EA, Tainaka K, Perrin D, Yukinaga H, Kuno A, Ueda HR (2015) Advanced CUBIC protocols for whole-brain and whole-body clearing and imaging. Nat Protoc 10:1709-1727 https://doi.org/10.1038/nprot.2015.085

52. Tarasoff-Conway JM, Carare RO, Osorio RS, Glodzik L, Butler T, Fieremans $E$ et al (2015) Clearance systems in the brain-implications for Alzheimer disease. Nat Rev Neurol 11:457-470. https://doi.org/10. 1038/nrneurol.2015.119

53. Vossel KA, Beagle AJ, Rabinovici GD, Shu H, Lee SE, Naasan G et al (2013) Seizures and epileptiform activity in the early stages of Alzheimer disease. JAMA Neurol 70:1158-1166 https://doi.org/10.1001/jamaneurol.2013.136

54. Weller RO, Subash M, Preston SD, Mazanti I, Carare RO (2008) Perivascular drainage of amyloid- $\beta$ peptides from the brain and its failure in cerebral amyloid angiopathy and Alzheimer's disease. Brain Pathol 18:253-266 https://doi.org/10.1111/j.1750-3639.2008.00133.x

55. Westmark CJ, Westmark PR, Beard AM, Hildebrandt SM, Malter JS (2008) Seizure susceptibility and mortality in mice that over-express amyloid precursor protein. Int J Clin Exp Pathol 1:157-168

56. Xu F, Kotarba AE, Ou-Yang MH, Fu Z, Davis J, Smith SO et al (2014) Earlyonset formation of parenchymal plaque amyloid abrogates cerebral microvascular amyloid accumulation in transgenic mice. J Biol Chem 289: 17895-17908 https://doi.org/10.1074/jbc.M113.536565

57. Xu Z, Xiao N, Chen Y, Huang H, Marshall C, Gao J et al (2015) Deletion of aquaporin-4 in APP/PS1 mice exacerbates brain A $\beta$ accumulation and memory deficits. Mol Neurodegener 10:58 https://doi.org/10.1186/s13024015-0056-1

58. Yang J, Lunde LK, Nuntagij P, Oguchi T, Camassa LM, Nilsson LN et al (2011) Loss of astrocyte polarization in the tg-ArcSwe mouse model of Alzheimer's disease. J Alzheimers Dis 27:711-722 https://doi.org/10.3233/JAD-2011-110725

59. Yang J, Zhang R, Shi C, Mao C, Yang Z, Suo Z et al (2017) AQP4 association with amyloid deposition and astrocyte pathology in the Tg-ArcSwe mouse model of Alzheimer's disease. J Alzheimers Dis 57:157-169 https://doi.org/ 10.3233/JAD-160957

\section{Publisher's Note}

Springer Nature remains neutral with regard to jurisdictional claims in published maps and institutional affiliations.

Ready to submit your research? Choose BMC and benefit from:

- fast, convenient online submission

- thorough peer review by experienced researchers in your field

- rapid publication on acceptance

- support for research data, including large and complex data types

- gold Open Access which fosters wider collaboration and increased citations

- maximum visibility for your research: over $100 \mathrm{M}$ website views per year

At BMC, research is always in progress.

Learn more biomedcentral.com/submissions 